\title{
The study of the relationship between pore structure and photocatalysis of mesoporous $\mathrm{TiO}_{2}$
}

\author{
BING GUO $^{a}$, HANGYAN SHEN ${ }^{\mathrm{a}, *}$, KANGYING SHU $^{\mathrm{a}}$, YAOWU ZENG ${ }^{\mathrm{b}}$ and \\ WENSHENG NING ${ }^{\mathrm{c}}$ \\ ${ }^{a}$ College of Materials Science and Engineering, China Jiliang University, Hangzhou 310018, China \\ ${ }^{\mathrm{b}}$ Center of Test and Analysis, Zhejiang University, Xixi Campus, Hangzhou 310028, China \\ ${ }^{\circ}$ College of Chemical Engineering and Materials, Zhejiang University of Technology, \\ Hangzhou 310032, China \\ e-mail: shenhangyan@yahoo.com.cn
}

MS received 30 July 2008; revised 24 September 2008

\begin{abstract}
Mesoporous titania was synthesized by a sol-gel method using the surfactants Span85 and $\mathrm{X} 114$ as the template. The pore structure was determined by the $\mathrm{N}_{2}$ adsorption/desorption method below $73 \mathrm{~K}$ and calculated using the BJH model. TEM characterizations show that the pores are formed through particle accumulation. Two kinds of channels, straight channels made of cylindrical capillaries and curved channels made of slit-shaped pores, exist in the bulk materials. The influence of the pore structure of mesoporous $\mathrm{TiO}_{2}$ on its photocatalytic performance was studied. The sample with higher porosity, better textural properties and straight channels are good for photocatalytic performance.
\end{abstract}

Keywords. Mesoporous $\mathrm{TiO}_{2}$; pore structure; photocatalytic performance.

\section{Introduction}

$\mathrm{TiO}_{2}$ is an effective catalytic material and has been intensively studied for sensors, ${ }^{1,2}$ as a photocatalyst, ${ }^{3}$ in solar cells, ${ }^{4}$ lithium-ion cells ${ }^{5}$ and many others. Many studies have reported that the surface properties of $\mathrm{TiO}_{2}$, including grain size, crystallization, morphology, specific surface area, surface state, and porosity clearly influence its photocatalytic activity. ${ }^{6-8}$

Mesoporous $\mathrm{TiO}_{2}$ has better properties in many respects than ordinary $\mathrm{TiO}_{2}$ because of its high specific surface area and uniform pore diameter. Mesoporous $\mathrm{TiO}_{2}$ was first synthesized through modified sol-gel routes in the presence of alklyphosphate surfactant templates in $1995 .{ }^{9}$ Since then, researchers have adopted different routes to the synthesis of $\mathrm{TiO}_{2}$ with the mesoporous structure such as the hydrothermal process using cetyltrimethylammonium bromide (CTAB) as a template agent, ${ }^{10}$ the ultrasonic irradiation method, ${ }^{11}$ the use of block copolymers, ${ }^{12}$ the hydrolysis of $\mathrm{TiOCl}_{2}$ aqueous solution at low temperature using octyl polyethylene oxide as the template agent, ${ }^{13}$ and so on. Though this

\footnotetext{
*For correspondence
}

mesoporous $\mathrm{TiO}_{2}$ has proved to have excellent performance as a photocatalyst there has been little investigation of the relationship between the pore structure and photocatalysis. In this paper, mesoporous $\mathrm{TiO}_{2}$ was synthesized by the sol-gel method using tetrabutyl titanate as the precursor and Span85 or X114 as the surfactant. The pore structure of mesoporous $\mathrm{TiO}_{2}$ was characterized by $\mathrm{N}_{2}$ adsorption/desorption isotherms, X-ray diffraction (XRD), scanning electron microscopy (SEM) and transmission electron microscopy (TEM) methods. The influence of the pore structure of mesoporous $\mathrm{TiO}_{2}$ on its photocatalytic performance was studied. The results show that the catalytic activity has a close relationship with the pore structure.

\section{Experimental}

\subsection{Synthesis of mesoporous $\mathrm{TiO}_{2}$}

Mesoporous $\mathrm{TiO}_{2}$ was synthesized by the sol-gel method. Span85 $\left(\mathrm{C}_{60} \mathrm{H}_{108} \mathrm{O}_{8}\right)$ and $\mathrm{X} 114\left(t-\mathrm{Oct}-\mathrm{C}_{6} \mathrm{H}_{4}-\right.$ $\left.\left(\mathrm{OCH}_{2} \mathrm{CH}_{2}\right)_{x} \mathrm{OH}, x=7-8\right)$ were chosen as the surfactants respectively. A homogeneous solution was obtained by stirring a mixture of $50 \mathrm{ml}$ ethanol and surfactant. The dosage of Span85 and X114 are 
$0.006 \mathrm{~mol}$ and $0.025 \mathrm{~mol} .17 \mathrm{~g}$ tetrabutyl titanate was dropped into the above solution and then allowed to react at $60^{\circ} \mathrm{C}$ overnight. The resulting sol solution was gelled at $80^{\circ} \mathrm{C}$ in air for 7 days. Mesoporous $\mathrm{TiO}_{2}$ was obtained by calcination of the gel at $500^{\circ} \mathrm{C}$ for $6 \mathrm{~h}$ in air to remove the surfactant species. The samples were designated as $\mathrm{TiO}_{2}-\mathrm{X} 114$ and $\mathrm{TiO}_{2}$-Span85 in this paper depending on the surfactant. $\mathrm{TiO}_{2}$ is the nano-titania as purchased from Sinopharm Chemical Reagent Co., Ltd.

\subsection{Photocatalytic performance}

Photocatalytic performance was tested by a study of the photo-degradation of acetone. The content of produced $\mathrm{CO}_{2}$ was analysed by a gas chromatograph GC112 equipped with a thermal conductivity detector (TCD) using TDX-101 as the chromatogram column.

\subsection{Characterization}

The $\mathrm{N}_{2}$ adsorption/desorption isotherms of mesoporous titania were measured on a Micromeritics ASAP 2020 instrument at a temperature below $73 \mathrm{~K}$. The sample was treated at $300^{\circ} \mathrm{C}$ before measurement. Surface areas of the samples were calculated from the adsorption isotherms by the BET method and the pore size distributions determined from desorption isotherms by the Barrett-Joiner-Halenda (BJH) method. The average pore size was calculated from the $t$-plot method.

XRD patterns of the samples were obtained on a Thermo ARL SCINTAG X'TRA X diffractometer (using $\mathrm{CuK} \alpha$ radiation, $\lambda=0.15406 \mathrm{~nm}$, scan range $2 \theta=15^{\circ} \sim 80^{\circ}$, scan rate $=0.02 \mathrm{~s}^{-1}$ ).

TEM was conducted on a JEM2010 (HR) instrument. SEM was conducted on a Hitachi S-4700 instrument.

\section{Results and discussion}

\subsection{Structure characterization}

The XRD patterns of $\mathrm{TiO}_{2}-\mathrm{X} 114$ and $\mathrm{TiO}_{2}-\mathrm{Span} 85$ are shown in figure 1 . The diffraction peaks at $25.28^{\circ}$, $37.80^{\circ}$ and $48.05^{\circ}$ are consistent with the (101), (004) and (200) peaks of anatase $\mathrm{TiO}_{2}$. The XRD results suggest that the samples prepared in this work have good anatase crystallization and the kind of surfactant has little influence on the nature of crystal formation.

Figure 2 shows the $\mathrm{N}_{2}$ adsorption/desorption isotherms of $\mathrm{TiO}_{2}-\mathrm{X} 114, \mathrm{TiO}_{2}-\mathrm{Span} 85$ and $\mathrm{TiO}_{2}$. The isotherms of $\mathrm{TiO}_{2}-\mathrm{X} 114$ and $\mathrm{TiO}_{2}-\mathrm{Span} 85$ are of type. ${ }^{14}$ and that of $\mathrm{TiO}_{2}$ is of type II. During the process of adsorption, single molecular layer adsorption occurred at relatively low pressure and then multi-molecular layer adsorption occurred at higher pressure. The larger are the sample pore sizes, the higher the pressure of capillary cohesion that occurred. ${ }^{14}$ As shown in figure 2 , the capillary cohesion of $\mathrm{TiO}_{2}$ occurred at the highest pressure and that of $\mathrm{TiO}_{2}-\mathrm{Span} 85$ occurred at the lowest pressure. It suggests that the sample $\mathrm{TiO}_{2}$ had the largest pore size and $\mathrm{TiO}_{2}$-Span85 had the smallest pore size. The hysteresis loop of $\mathrm{TiO}_{2}-\mathrm{X} 114$ is the $\mathrm{H} 1$ type, ${ }^{14}$ which can originate from independent cylindrical capillaries. The hysteresis of nanometer $\mathrm{TiO}_{2}$ is $\mathrm{H} 3,{ }^{14}$ which suggested that the sample has slit-

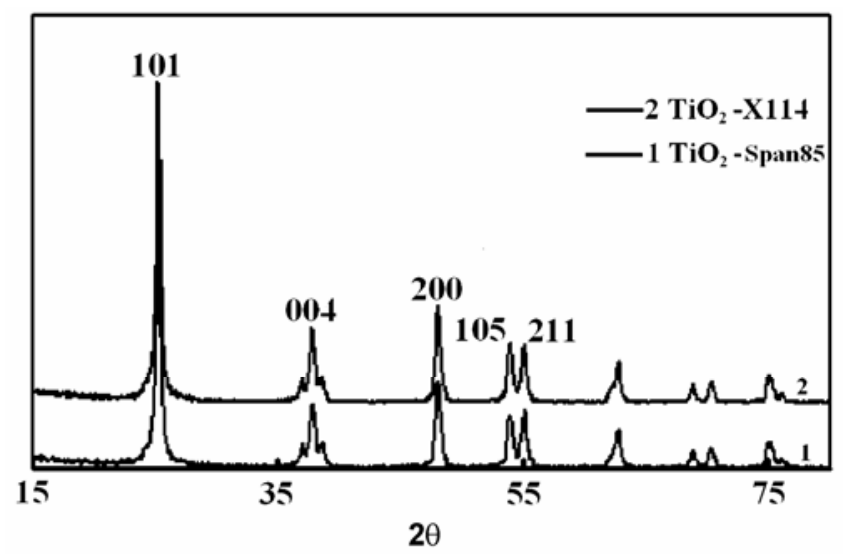

Figure 1. X-ray patterns of sample $\mathrm{TiO}_{2}-\mathrm{X} 114$ and $\mathrm{TiO}_{2}-\mathrm{Span} 85$.

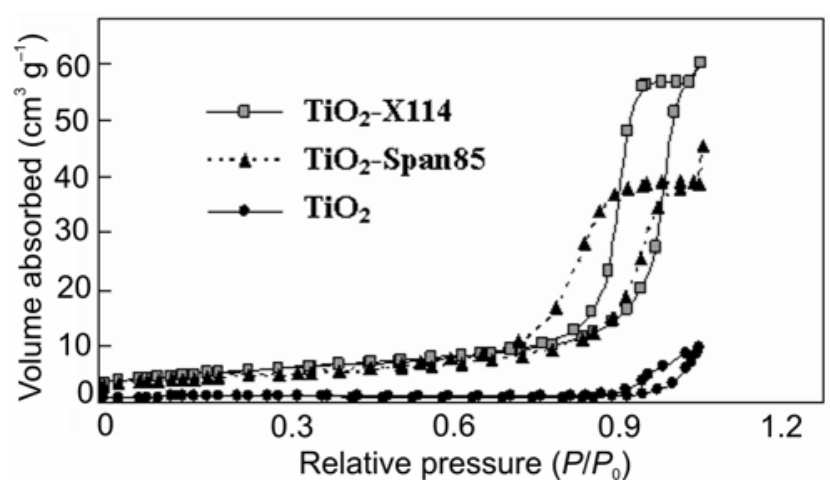

Figure 2. $\mathrm{N}_{2}$ adsorption/desorption isotherms of $\mathrm{TiO}_{2}-$ $\mathrm{X} 114, \mathrm{TiO}_{2}-\mathrm{Span} 85$ and $\mathrm{TiO}_{2}$. 
shaped pores. The hysteresis loop of $\mathrm{TiO}_{2}-\mathrm{Span} 85$ is the $\mathrm{H} 1+\mathrm{H} 3$ type, which indicated that this sample has some slit-shaped pores. Figure 3 is the pore size distribution of sample derived from the desorption

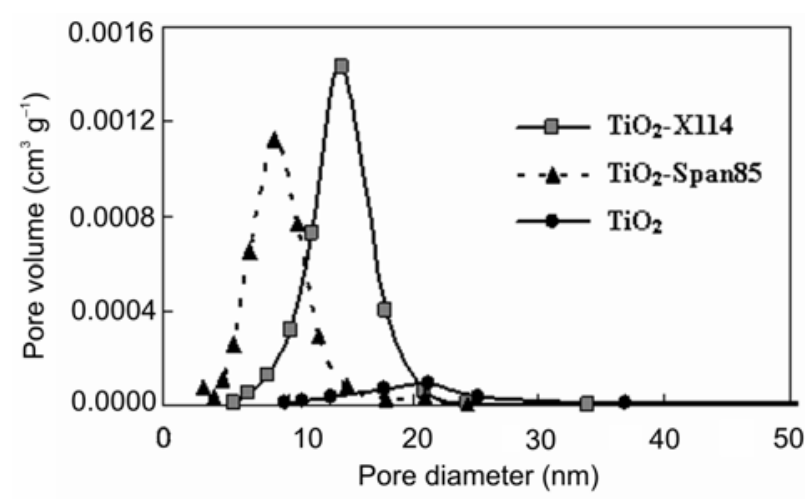

Figure 3. Pore size distributions of $\mathrm{TiO}_{2}-\mathrm{X} 114, \mathrm{TiO}_{2}-$ Span85 and $\mathrm{TiO}_{2}$ derived from desorption branches of $\mathrm{N}_{2}$ adsorption/desorption isotherms.

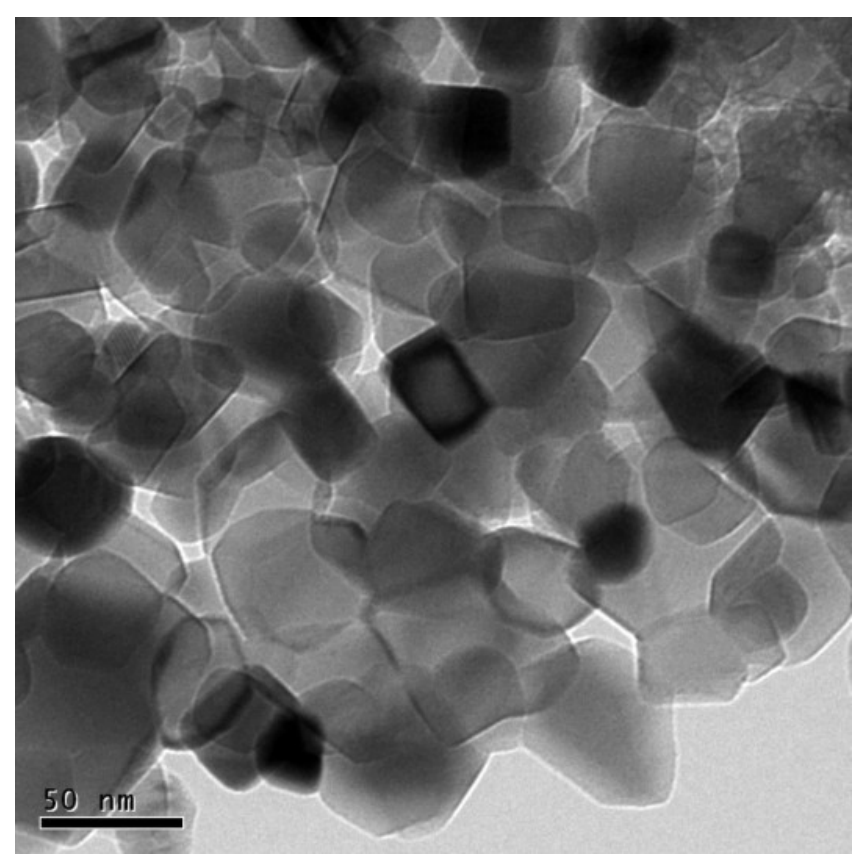

Figure 4. TEM image of sample $\mathrm{TiO}_{2}-\mathrm{X} 114$.

Table 1. The specific surface area, pore volume and the average pore size of samples.

\begin{tabular}{lccc}
\hline Sample & $\begin{array}{c}\text { Surface area } \\
\left(\mathrm{m}^{2} / \mathrm{g}\right)\end{array}$ & $\begin{array}{c}\text { Pore volume } \\
\left(\mathrm{cm}^{3} / \mathrm{g}\right)\end{array}$ & $\begin{array}{c}\text { Average pore } \\
\text { size }(\mathrm{nm})\end{array}$ \\
\hline $\mathrm{TiO}_{2}-\mathrm{X} 114$ & 18.96 & 0.093 & $14 \cdot 4$ \\
$\mathrm{TiO}_{2}-\mathrm{Sp} p \mathrm{n} 85$ & 15.8 & 0.06 & $10 \cdot 1$ \\
$\mathrm{TiO}_{2}$ & 3.58 & 0.0094 & $24 \cdot 38$ \\
\hline
\end{tabular}

branch of the $\mathrm{N}_{2}$ adsorption/desorption isotherm. Samples $\mathrm{TiO}_{2}-\mathrm{Span} 85$ and $\mathrm{TiO}_{2}-\mathrm{X} 114$ have a narrow pore size distribution and most of the pore diameters are in the range of $10-20 \mathrm{~nm}$. The sample $\mathrm{TiO}_{2}$ has a wide pore size distribution with most of the pore diameters in the range of $10-30 \mathrm{~nm}$. The surface area, pore volume and the average pore size of samples

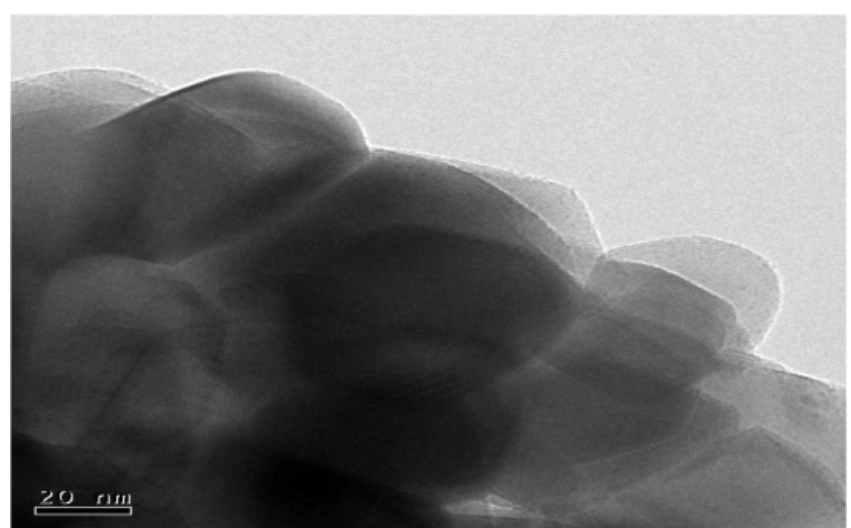

$\mathrm{TiO}_{2}$

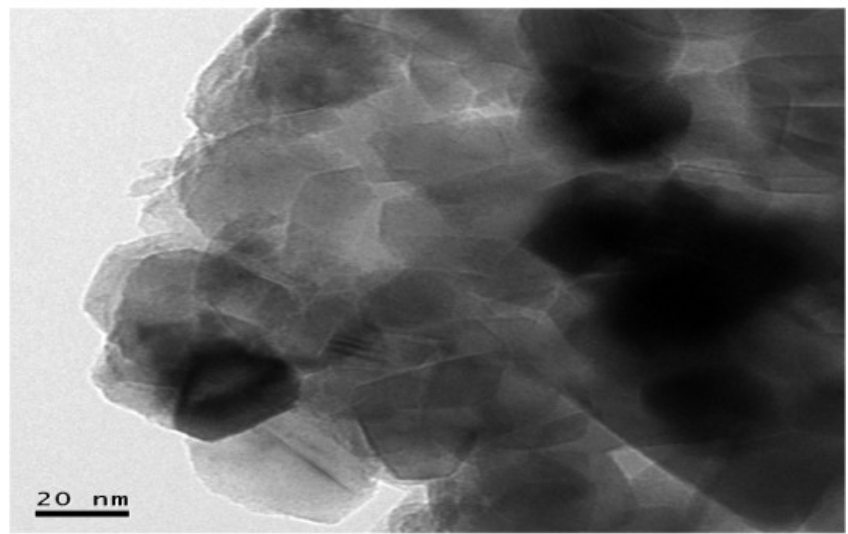

$\mathrm{TiO}_{2}-\mathrm{Span} 85$

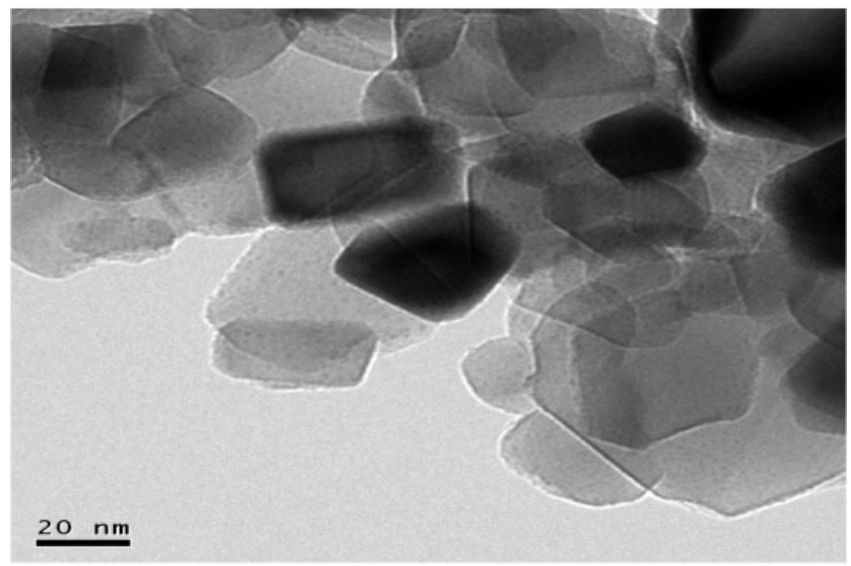

$\mathrm{TiO}_{2}-\mathrm{X} 114$

Figure 5. TEM images of $\mathrm{TiO}_{2}-\mathrm{X} 114, \mathrm{TiO}_{2}-\mathrm{Span} 85$ and $\mathrm{TiO}_{2}$. 
are summarized in table 1. Although the sample $\mathrm{TiO}_{2}$ has the largest average pore size, its surface area and pore volume is smallest which indicated that the porosity is very low. The textural properties

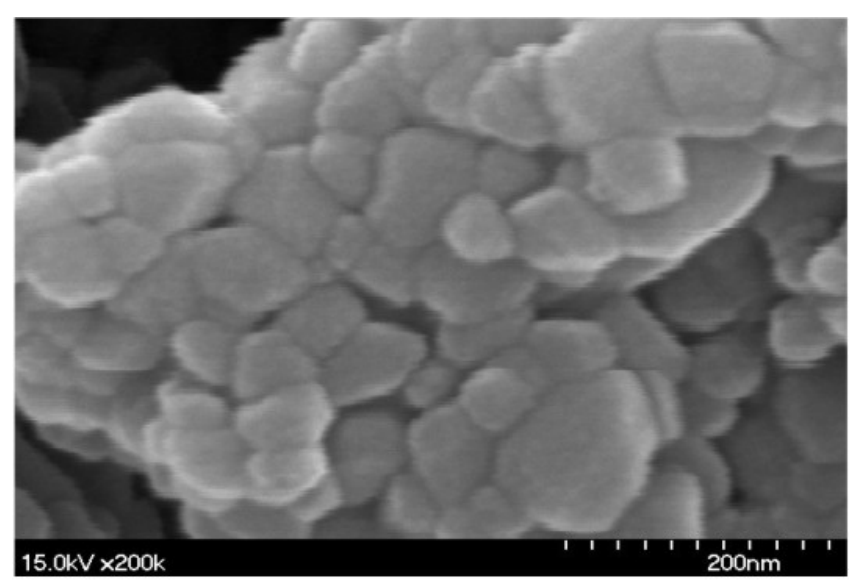

$\mathrm{TiO}_{2}$

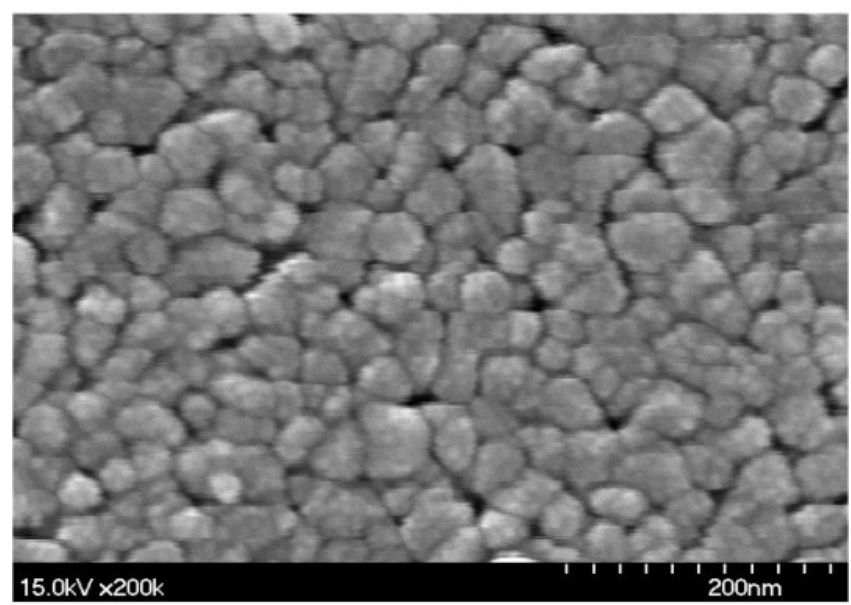

$\mathrm{TiO}_{2}-\mathrm{Span} 85$

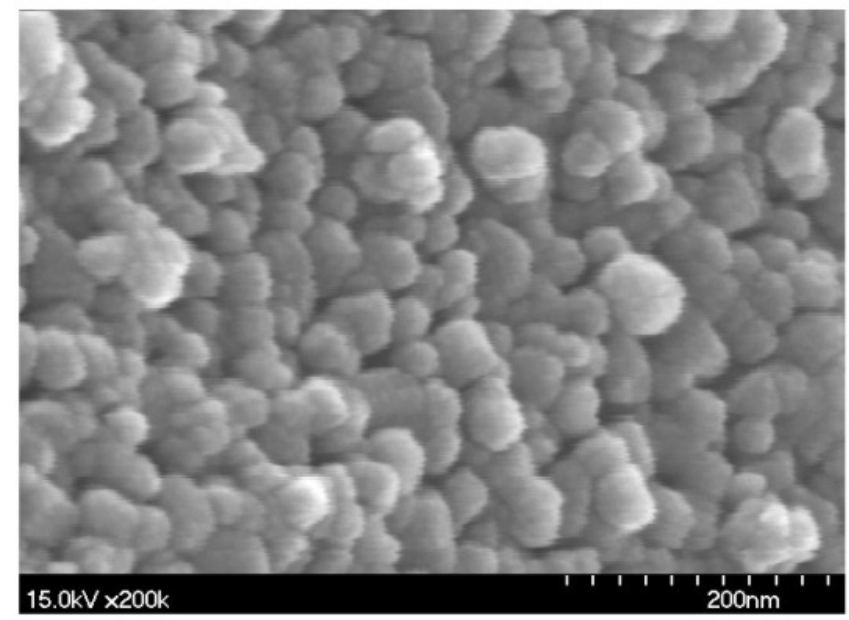

$\mathrm{TiO}_{2}-\mathrm{X} 114$

Figure 6. $\mathrm{SEM}$ images of $\mathrm{TiO}_{2}-\mathrm{X} 114, \mathrm{TiO}_{2}-\mathrm{Span} 85$ and $\mathrm{TiO}_{2}$. of $\mathrm{TiO}_{2}-\mathrm{X} 114$ are greater than those of $\mathrm{TiO}_{2}-$ Span85.

Figure 4 shows the TEM image of $\mathrm{TiO}_{2}-\mathrm{X} 114$. Nano-particles were packed randomly and pore channels were formed from the particle packing. The translucent region represents the straight channels and the gray region represents the curved channels. Figure 5 shows the TEM images of $\mathrm{TiO}_{2}-\mathrm{X} 114$, $\mathrm{TiO}_{2}-\mathrm{Span} 85$ and $\mathrm{TiO}_{2}$. It is clear that $\mathrm{TiO}_{2}$ has many shadow regions indicating that the nanoparticles have agglomerated. $\mathrm{TiO}_{2}-\mathrm{X} 114$ has much more translucent region than $\mathrm{TiO}_{2}-\mathrm{Span} 85$ which suggests that $\mathrm{TiO}_{2}-\mathrm{X} 114$ has many straight channels. $\mathrm{TiO}_{2}$-Span85 has much more gray regions which suggest that many curved channels were formed. The results of the TEM accord well with that of the $\mathrm{N}_{2}$ adsorption/desorption test. The $\mathrm{H} 3$ hysteresis loop of $\mathrm{TiO}_{2}$ suggested that there are curved channels in the bulk. $\mathrm{TiO}_{2}$-Span85 has many curved channels consisting mainly of slit-shaped pores. $\mathrm{TiO}_{2}-\mathrm{X} 114$ has many straight channels consisting mainly of independent cylindrical capillaries.

Figure 6 shows the SEM images of $\mathrm{TiO}_{2}-\mathrm{X} 114$, $\mathrm{TiO}_{2}$-Span85 and $\mathrm{TiO}_{2}$. It indicates that particles of $\mathrm{TiO}_{2}$ congregate together so densely that few gaps exist between the pores. In contrast, the particles of $\mathrm{TiO}_{2}-\mathrm{X} 114$ and $\mathrm{TiO}_{2}$-Span85 congregate loosely. The particle size of $\mathrm{TiO}_{2}-\mathrm{X} 114$ is slightly larger than that of $\mathrm{TiO}_{2}$-Span85. The agglomeration of $\mathrm{TiO}_{2}$ particles resulted in have low surface area and pore volume.

\subsection{Photocatalytic activity}

The pore-structure of mesoporous $\mathrm{TiO}_{2}$ influences the adsorption of photoelectrons, reagents and prod-

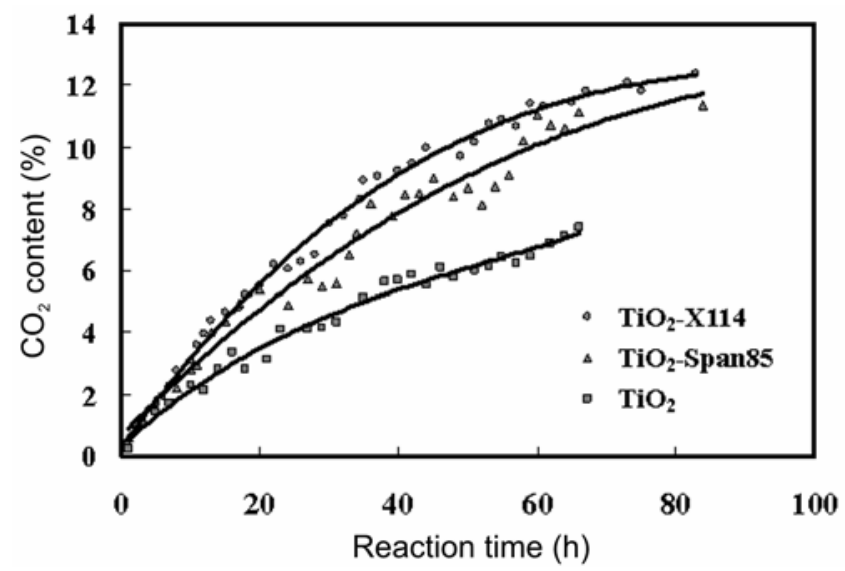

Figure 7. Photocatalytic performances of $\mathrm{TiO}_{2}-\mathrm{X} 114$, $\mathrm{TiO}_{2}-\mathrm{Span} 85$ and $\mathrm{TiO}_{2}$. 
ucts on the surface site. As a result, the photocatalytic activity of mesoporous $\mathrm{TiO}_{2}$ will change with its pore structure. Figure 7 shows the dependence of the content of product $\mathrm{CO}_{2}$ on the reaction time. The photocatalytic activity of nanometer $\mathrm{TiO}_{2}$ is lower than that of mesoporous $\mathrm{TiO}_{2}-\mathrm{X} 114$ and $\mathrm{TiO}_{2}$-Span85. From the structure data, nanometer $\mathrm{TiO}_{2}$ has many slit-gap pores with a $\mathrm{H} 3$ hysteresis loop and low porosity resulting in its small surface area and pore volume. Its structure is not suitable for the adsorption of photoelectrons and the diffusion of reagent and product. $\mathrm{TiO}_{2}-\mathrm{Span} 85$ has many curved channels, a lower specific surface area, smaller pore volume and narrower pore diameter than $\mathrm{TiO}_{2}-\mathrm{X} 114$, which limit the diffusion of reagent and product. As a result, $\mathrm{TiO}_{2}$-Span85 has lower photocatalytic performance than that of $\mathrm{TiO}_{2}$ X114.

\section{Conclusions}

In this paper, mesoporous $\mathrm{TiO}_{2}$ was synthesized using the sol-gel method with surfactants Span85 and X114. The pore structures of the samples were determined by $\mathrm{N}_{2}$ adsorption/desorption isotherms and TEM methods. Results indicated that the particles of mesoporous $\mathrm{TiO}_{2}$ are arranged randomly and the pore channels are formed from the packing of particles. Two kinds of pore channels exist in the bulk samples. One is the curved channel composed mainly of slit-shaped pores. Another is the straight channel mainly formed by independent cylindrical capillaries. The photocatalytic activity of mesoporous $\mathrm{TiO}_{2}$ has a close relationship to its pore structure. The sample with higher porosity, better textural properties and straight channel are good for photocatalytic performance. More detailed research into the dependence of pore structure on the photocatalytic activity is under investigation.

\section{Acknowledgements}

This work was financially supported by the National Science Foundation of China (no. 20701034) and Zhejiang Provincial Top Discipline.

\section{References}

1. Savage N, Chwieroth B, Ginwalla A, Patton B R, Akbar S A and Dutta P K 2001 Sens. Actuator B79 17

2. Yasuhiro Shimizu, Takeo Hyodo and Makoto Egashira 2004 Eur. Ceram. Soc. 241389

3. Yu J C, Yu J, Ho W and Zhao J 2002 J. Photochem. Photobiol., A Chem. 148331

4. George Phani, Gavin Tulloch, David Vittorio and Igor Skryabin 2001 Renew Energy 22303

5. Kavan L, Rathouský J, Grätzel M, Shklover V and Zukal A 2001 Microporous Mesoporous Mater. 44-45 653

6. Subramanian V, Wolf E E and Kamat P V 2004 J. Am. Chem. Soc. 1264943

7. Ohtani B, Ogawa Y and Nishimoto S 1997 J. Phys. Chem. B101 3746

8. Yu J G, Wang B, Cheng M and Zhou $2007 \mathrm{Appl}$. Catal. B: Environ. 69171

9. Antonelli D M and Ying J Y 1995 Angew. Chem. Int. Ed. 342014

10. Peng T Y, Zhao D, Dai K, Shi W and Hirao K 2005 Phys. Chem. B109 4947

11. Yu J, Yu J C, Lueng M K P, Ho W, Cheng B, Zhao X and Zhao J 2003 J. Catal. 21769

12. Smarsly B, Grosso D, Brezesinski T, Pinna N, Boissiere C, Antonietti M and Sanchez C 2004 Chem. Mater. 162948

13. Li Y, Lee N H, Lee E G, Song J S and Kim S J 2004 Chem. Phys. Lett. 389124

14. Rojas F, Kornhauser I, Felipe C, Esparza J M, Cordero S, Dominguez A and Riccardo J L 002 Phys. Chem. Chem. Phys. 42346 